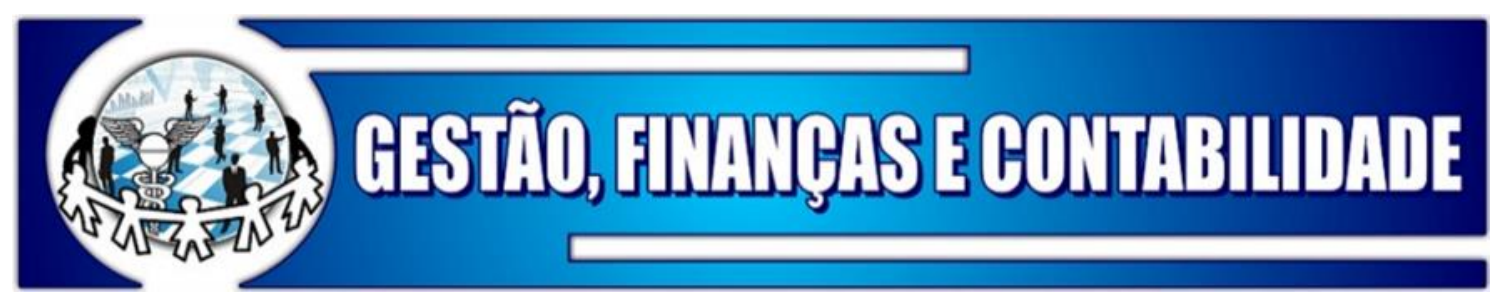

\title{
A TEORIA DE OPÇÕES REAIS NA GESTÃO DE INVESTIMENTOS NA INDÚSTRIA 4.0: UM ESTUDO DE CASO
}

\section{THE REAL OPTIONS THEORY IN INVESTMENT MANAGEMENT OF THE INDUSTRY 4.0: A CASE STUDY}

\section{LA TEORÍA DE LAS OPCIONES REALES EN LA GESTIÓN DE INVERSIONES EN LA INDUSTRIA 4.0: UN ESTUDIO DE CASO}

Felipe Heidrich

https://orcid.org/0000-0002-8281-2189 Mestre em Engenharia e Gestão de Inovação (UFABC)

E-mail: heidrichfelipe@gmail.com

Diogo Martins Gonçalves de Morais https://orcid.org/0000-0001-5681-4044

Professor da Faculdade de Tecnologia Termomecanica (FTT) Doutor em Administração pela Universidade Municipal de São Caetano do Sul (USCS)

E-mail: pro7113@cefsa.edu.br

Júlio Francisco Blumetti Facó

https://orcid.org/0000-0002-8155-5547

Professor da Universidade Federal do ABC (UFBAC) Doutor em Administração pela Fundação Getúlio Vargas (FGV) E-mail: julio.faco@ufabc.edu.br

\section{RESUMO}

Com a finalidade de validar uma metodologia para avaliação de projetos de investimentos caracterizados como indústria 4.0, o presente estudo propõe a aplicação da Teoria das Opções Reais como ferramenta de análise de investimentos em um projeto aderente a esse contexto, aplicada a um estudo de caso real de fabricação de rolamentos de grande porte em uma indústria paulista. A partir dos resultados reais dessa aplicação, é possível concluir que a metodologia utilizada das opções reais se mostrou eficiente na mitigação de riscos e flexibilização gerencial na tomada de decisão no estudo de caso apresentado. Palavras-Chave: Indústria 4.0. Teoria de Opções Reais. Investimento em Projetos de Inovação. 


\begin{abstract}
In order to validate a methodology for evaluating investment projects characterized as Industry 4.0, the present study proposes the application of the Real Options Theory as an investment analysis tool in a project adhering to this context applied to a real case study in a large bearing manufacturing industry of São Paulo. From the real results of this application, it is possible to conclude that the methodology used for the real options proved to be efficient in risk mitigation and managerial flexibility on decision-making in the case presented.
\end{abstract}

Keywords: Industry 4.0. Theory of Real Options. Innovation Investment Projects.

\title{
RESUMEN
}

Con el fin de validar una metodología de evaluación de proyectos de inversión caracterizados como industria 4.0, este estudio propone la aplicación de la Teoría de Opciones Reales como herramienta de análisis de inversiones en un proyecto adherente a este contexto, aplicado a un caso de estudio real. fabricación de grandes rodamientos en una industria de São Paulo. A partir de los resultados reales de esta aplicación, es posible concluir que la metodología empleada de las opciones reales resultó ser eficiente en la mitigación de riesgos y flexibilidad gerencial en la toma de decisiones en el caso de estudio presentado.

Palabras Clave: Industria 4.0. Teoría de las opciones reales. Inversión en Proyectos de Innovación.

\section{INTRODUÇÃO}

Em dois universos diferentes, o conceito de Indústria 4.0 ou Manufatura Inteligente podem ser nomes dados ao mesmo fenômeno, que será o contexto básico desse estudo. De um lado a Alemanha encabeça a posição da Indústria 4.0 como um marco da utilização das tecnologias digitais para uma Quarta Revolução Industrial, sustentada por tecnologias de inteligência artificial que proporcionam a existência de fábricas inteligentes e máquinas conversando com máquinas (CONSULTING GROUP, 2015).

Por outro lado, os Estados Unidos também têm tratado o assunto como diretriz prioritária para reformulação industrial, denominado Manufatura Inteligente, mas com um foco maior em desenvolvimento de novas tecnologias, tais como impressão 3D, análises preditivas e uso a fundo da Indústria da Internet das Coisas em serviços (ACCENTURE TECHNOLOGY, 2016).

No caso da indústria brasileira, ainda há a preocupação prioritária de aumentar de eficiência para, posteriormente, olhar para aplicações mais voltadas ao desenvolvimento de novos produtos e aos novos modelos de negócio.

Para se adaptarem rapidamente ao ambiente acirrado de competição e incerteza futura, as empresas são forçadas a buscar adaptações rápidas, onde procuram investir seu capital em empreendimentos que gerem destaque competitivo e expansão no seu crescimento (YOSHIMURA, 2008).

Nesse contexto, há a necessidade de uma análise econômica de investimentos para esta indústria, que sobreponha as limitações da tradicional metodologia de avaliação de projetos, que consiste em descontar o fluxo de caixa projetado a uma taxa que defina seu risco, avaliando seu Valor Presente Líquido (VPL). 
Diante disso, uma ferramenta mais adequada para quantificar as flexibilidades gerenciais em projetos corporativos é conhecida por Teoria de Opções Reais (TOR), a qual avalia com melhor precisão a capacidade da gestão em adaptar-se a novas informações.

Nessa direção, o presente artigo tem o objetivo de apresentar um estudo de caso que envolve a utilização das Opções Reais em um contexto da Indústria 4.0, por meio de uma metodologia desenvolvida para identificar o momento adequado de realizar expansões ou não de investimentos.

Para a operacionalização dessa proposta, avaliou-se a aplicação da Teoria das Opções Reais, enquanto metodologia de avaliação de investimentos de um projeto real de manufatura inteligente, de fabricação de rolamentos de grande porte.

A indústria envolvida nesse estudo está localizada no Brasil, que por diretriz de sua matriz, na Alemanha, está desenvolvendo projetos para modernização e possibilitando a incorporação dos conceitos de Indústria 4.0, utilizando a internet das coisas como plataforma de direcionamento para os projetos de investimentos na busca de melhor efetividade produtiva e geração de valor ao cliente.

No presente estudo será adotado o conceito da Indústria 4.0 e seus termos mais comuns, tais como: Fábricas Inteligentes, Computação em nuvem, Big Data, etc, por se assemelhar ao foco que o Brasil tem sinalizado, de acordo com CNI (2016) como estratégia competitiva.

A relevância deste estudo não está somente na aplicação de um modelo financeiro mais atual em que são considerados os fatores de riscos e incertezas no qual estão inseridas as empresas no complexo mercado atual.

Para a apresentação do estudo proposto, o artigo encontra-se estruturado em cinco seções, a saber: a presente seção, denominada INTRODUÇÃO, em que se apresenta o contexto da pesquisa, os conceitos envolvidos, a justificativa e o objetivo do estudo; o REVISÃO DA LITERATURA, em que se apresenta as ideias centrais acerca da Indústria 4.0 e sobre a Teoria das Opções Reais, a seção ESTUDOS DE CASO, em que se apresenta o estudo de caso realizado e se discute os resultados da utilização da ferramenta em um caso real, e por fim, a seção CONCLUSÕES, em que se apresenta as conclusões do estudo.

\section{REVISÃO DA LITERATURA}

Nessa seção são apresentados os conceitos que servem de base para todo o presente estudo, a saber: a Indústria 4.0 e a teoria das Opções Reais.

\subsection{A INDÚSTRIA 4.0}

O fenômeno denominado Indústria 4.0 tem chamado a atenção de muitos pesquisadores de diversas áreas, como engenharia, economia, gestão e tecnologia da informação, como apontado por Hermann (2016). Este interesse pelo assunto iniciou-se após o Governo Federal da Alemanha anunciar a Indústria 4.0 como uma iniciativa estratégica com o objetivo de reposicionamento frente às tecnologias de ponta e competitividade para as suas indústrias. 
A proposta do Governo Alemão é suportada na ideia de que a Indústria 4.0 será parte integrante da estratégia de alta tecnologia para que em 2020 a Alemanha lidere este movimento de inovação tecnológica (KAGERMANN, LUKAS e WAHLSTER, 2011).

Desde este marco em 2011, quando uniu instituições do governo, indústria e acadêmicos para iniciarem estudos mais detalhados e profundos sobre este tópico. Consequentemente, muitas publicações de artigos e conferências relacionadas a este tópico surgiram (BAUERNHANSL, HOMPEL e VOGEL-HEUSER, 2014).

A produção industrial evolui do modelo prévio das três revoluções anteriores, que focaram na centralização e produção em massa para alcançar uma economia essencialmente em maior escala, para uma norteada pela customização de massa e flexibilidade, com a produção de produtos tão próxima dos centros de venda quanto possível. O cliente cada vez mais exige produtos customizados para os seus gostos, tendo o processo produtivo que acompanhar tamanhas exigências.

Em vez de criar e gerenciar inventários, o setor industrial busca hoje construir uma cadeia de suprimentos integrada que se ajusta dinamicamente, capaz de se adaptar aos requisitos logísticos em tempo real e atender as demandas dos fornecedores e clientes. Isso inclui a habilidade de prever e tomar ações corretivas na medida em que são necessárias. Outra forma de apresentar a Indústria 4.0 é dada por Davies (2015):

"Indústria 4.0 é um termo aplicado a um grupo de transformações rápidas no desenho da fabricação, operação e manutenção de sistemas de fabricação e produtos. A Indústria 4.0 é uma alusão a uma possível quarta revolução industrial do mundo, sucedendo as três revoluções anteriores" (DAVIES, 2015).

A Chanceler alemã, Angela Merkel, aponta a Indústria 4.0 como "a transformação abrangente de toda a esfera da produção industrial através da fusão da tecnologia digital e a internet com a indústria convencional". Desta forma, tudo dentro e em torno de uma operação de produção (fornecedores, planta, distribuidores, produtor) será digitalmente conectada, fornecendo uma cadeia de valor altamente integrada.

Em Chukwuekwe (2016) são apresentados de forma mais ampla os principais componentes tecnológicos da Indústria 4.0, sendo definidos e apontados por, por sua vez, assim: 1)Big Data, 2) Computação em Nuvem, 3) Internet dos Serviços, 4) Internet das Coisas, 5) CPS (Cyber Physical System), 6) Impressão 3D e 7) Manufatura Inteligente. Cada componente possui suas características e diversas tecnologias que as compõem, sendo cada um deles complexos e repletos de detalhes. A Figura 1 representa o cenário que compõem a Indústria 4.0 e seus componentes: 
Figura 1 - Indústria 4.0 e seus componentes

Fonte: Elaborado pelos autores

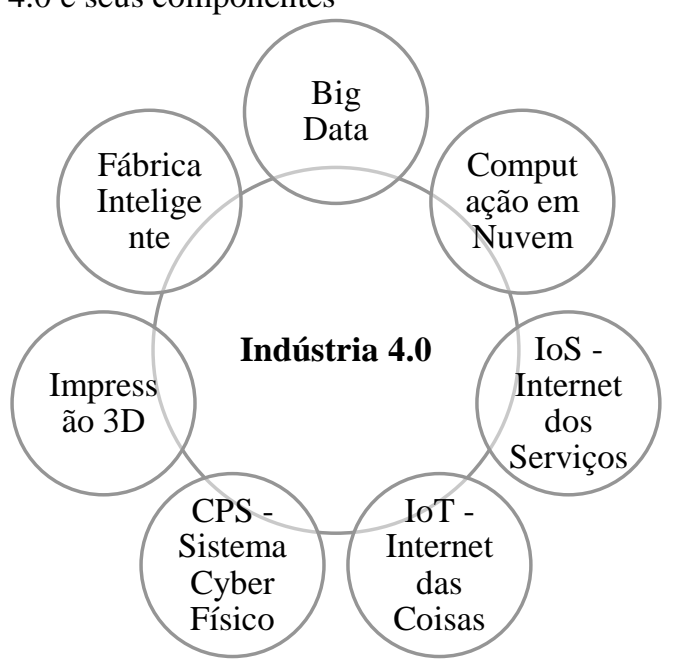

1) Big Data - Volume de dados

Os grandes volumes de dados estarão no centro do desenvolvimento do conceito de manutenção preditiva dentro do ambiente da Indústria 4.0, mas precisam ser processados e analisados por profissionais competentes e capacitados.

\section{2) Computação em Nuvem}

A definição fornecida pelo Instituto Nacional de Padrões e Tecnologia (NIST) é de que a computação em nuvem é um modelo para permitir acesso livre a uma vasta quantidade de informações compartilhadas através de recursos computacionais configuráveis por exemplo, redes, servidores, armazenamento, aplicativos e serviços que podem ser rapidamente provisionados e liberados com um esforço mínimo de gerenciamento ou interação com o provedor de serviços (MELL et al, 2011).

3) IoS - Internet dos Serviços

A IoS é constituído por participantes, uma infraestrutura de serviços, modelos de negócio e os próprios serviços. Os serviços são oferecidos e combinados em serviços de valor agregado por vários fornecedores. Eles são comunicados aos usuários, bem como aos consumidores e são acessados por eles através de vários canais (BUXMANN, HESS e RUGGABER, 2009, P.341).

4) IoT - Internet das Coisas

A Internet das Coisas se refere a uma rede em rede, na qual muitos objetos estão conectados (ATZORI, et al 2010).

5) CPS- Sistema CiberFísico

Os Sistemas Ciberfísicos (CPS) são integrações de computação e processos físicos (O’HALLORAN e KVOCHKO, 2015).

6) Impressão 3D

A tecnologia de impressão 3D é uma tecnologia importante para criação de protótipos auxiliares no processo de desenvolvimento de novos produtos, bem como, suas simulações testes de forma preliminar.

7) Manufatura Inteligente ou Fábrica Inteligente

Fábrica inteligente é uma visão para a fábrica do futuro, onde tanto os produtos manufaturados e as linhas de produção de engenharia fazem parte de um sistema 
inteligente que pode falar ou controlar uns aos outros por meio de comunicação máquina a máquina (M2M) ou outros algoritmos inteligentes.

\subsection{A TEORIA DAS OPÇÕES REAIS}

Segundo Rigolon (1999), as empresas e instituições financeiras usam, em geral, dois métodos tradicionais de análise de projetos: as regras do valor presente líquido (VPL) e da taxa interna de retorno (TIR). As decisões a partir destes métodos tradicionais para os projetos com VPL positivo ou TIR superior à taxa de desconto seriam, a princípio, os mais atrativos e candidatos a ter algum tipo de investimento, em relação a projetos com VPL negativo ou TIR inferior à taxa de desconto. Além disso, projetos com maiores VPL ou TIR identificariam uma alocação mais eficiente dos recursos.

Ao longo das duas últimas décadas, entretanto, a eficiência desses métodos vem sendo fortemente questionada. Em Dixit e Pindyck (1994), por exemplo, argumentam que a sua aplicação pode induzir a decisões de investimento equivocadas. A razão é que eles ignoram duas características importantes dessas decisões:

1) A irreversibilidade, ou seja, o fato de que o investimento é um custo irreversível, de modo que o investidor não consegue recuperá-lo totalmente em caso de arrependimento;

2) A possibilidade de adiamento da decisão de investir.

Essas características, juntamente com a incerteza sobre o futuro, fazem com que a oportunidade de investimento seja análoga a uma opção financeira, segundo Dixit e Pindyck (1994), opções reais são úteis para identificar, compreender, valorar, priorizar, selecionar, otimizar e gerenciar estratégia de negócios, bem como a melhor alocação nas decisões de aporte de capital.

$\mathrm{Na}$ presença de um cenário de incerteza, gerado por exemplo, em variações macroeconômicas, instabilidade políticas, influência da natureza, etc., uma empresa com uma oportunidade de investimento em um projeto qualquer se torna detentora de uma opção, ou seja, tem o direito - mas não a obrigação - de comprar um ativo (o projeto), a um preço de exercício (o valor do investimento).

Recentemente muitos economistas e pesquisadores têm explorado o conceito básico de que o pensamento de investimento como opções muda substancialmente a teoria e prática acerca do processo de tomada de decisão em investimento de capital. Nesta abordagem, o projeto é visto como uma opção que pode ser exercida ou não, segundo as condições do mercado. A Teoria das Opções Reais vale-se dos métodos de precificação de opções financeiras para avaliar os projetos (MIRANDA, 2005).

A análise de opções reais é uma abordagem sistemática metodológica e de solução integrada utilizando teoria financeira, análise econômica, ciências de administração e decisão, estatística, e modelagem econométrica na aplicação da teoria das opções para avaliar ativos físicos reais, em oposição a ativos financeiros. Esta análise está inserida num ambiente de negócio dinâmico e repleto de incertezas, onde as decisões são flexíveis nos contextos da estratégia de tomada de decisões em investimento de capital, da avaliação de oportunidades de investimento e da projeção de capital (MUN, 2003).

Segundo Miranda (2005), são necessários quatro passos para o processo de avaliação de Opções Reais, sendo que o primeiro passo é a análise padrão do valor presente do projeto com emprego de técnicas tradicionais. 
O segundo passo é a construção de uma árvore de eventos, baseada em um conjunto de incertezas combinadas que influenciam a volatilidade do projeto. Na maioria dos casos, pressupõe-se que as múltiplas incertezas que influenciam o valor de um projeto podem ser combinadas por meio de uma análise de Monte Carlo, em uma única incerteza: a distribuição dos retornos do projeto. Essa estimativa de volatilidade é utilizada na construção da árvore binomial.

O terceiro passo no processo de estimativa do valor de um projeto em termo de opções é a determinação das decisões gerenciais a serem tomadas nos nós da árvore de eventos, para transformá-la em uma árvore de decisões. As árvores de eventos modelam o conjunto de valores que o ativo subjacente sujeito a risco pode assumir ao longo do tempo. A árvore de decisão mostra os retornos das decisões ótimas, condicionadas às situações que se apresentam. Portanto, seus retornos são os que resultariam da opção, ou opções, que são avaliados.

O último passo é a avaliação dos retornos da árvore de decisões obtida.

O valor de um investimento ou de uma empresa deve considerar a sua capacidade operacional de geração de caixa mais o valor das oportunidades gerenciais embutidas. Projetos que apresentam valor presente negativo podem ser eventualmente viáveis, caso não tenham sido contempladas as flexibilidades embutidas no processo de avaliação. Enquanto opções financeiras são baseadas em ativos de referência negociáveis no mercado de capitais (ações, índices, moedas, etc.), as opções reais são baseadas nas oportunidades estratégicas embutidas nos projetos de investimento. As negociações das flexibilidades são decorrentes da implementação dos projetos e da negociação desses projetos entre agentes.

No presente estudo será utilizado a abordagem binomial, que é a mais simples das fórmulas de precificação de opções. Segundo Monteiro (2003), é o modelo visualmente mais simples e intuitivo para a avaliação do preço de opção. O modelo binomial tem sido também o modelo mais utilizado por praticantes que buscam nas opções uma forma de gerenciamento de seus investimentos em ativos reais.

A fórmula de precificação binomial assume que o preço do ativo objeto varia de forma discreta com saltos para cima e para baixo. O projeto pode, então, assumir somente dois valores diferentes a partir de um ponto no tempo. Observe o exemplo a seguir.

Tabela 1 - Exemplo de Modelo Binomial

Variáveis
$\frac{\text { Valor do Preço }(\mathrm{V})=\mathrm{R} \$ 100}{\text { Subir }(\mathrm{s})=1,1}$
$\frac{\text { Descer }(\mathrm{d})=1 / \mathrm{s}=0,90909}{\text { Probabilidades }(\mathrm{p} \mathrm{e} \mathrm{q})}$
$\frac{\mathrm{p}=0,5}{\mathrm{q}=1-\mathrm{p}=0,5}$

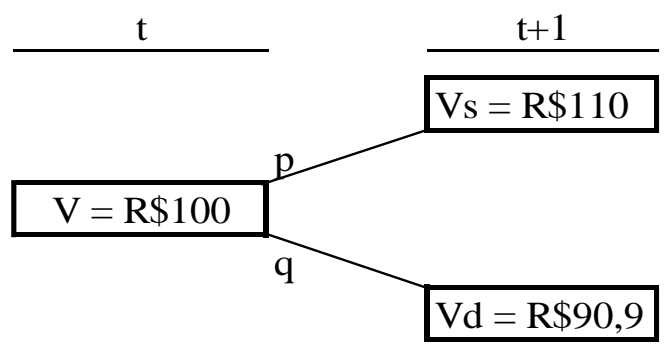

Fonte: Elaborado pelos autores

$\mathrm{Na}$ Tabela 1 o preço do projeto é $\mathrm{V}$ no tempo t e pode subir para Vs ou cair para $\mathrm{Vd}$ no tempo $\mathrm{t}+1$. Estes movimentos para cima e para baixo têm as probabilidades correspondentes a p e $q=(1-p)$, exemplificadas acima com valores atribuídos pelo autor.

A aplicação desta metodologia possui limites, dos quais precisam ser considerados no que tange à tomada de decisão. 
A Teoria de Opções Reais na Gestão de Investimentos

na Indústria 4.0: um Estudo de Caso

Em Kulatilaka e Perotti (1998) são mapeados os principais limites desta aplicação, sendo eles citados a seguir:

- Aproximações imperfeitas: quando não se tem o preço do produto em questão e por isso aproxima o valor de um similar;

- Ausência de liquidez: baixo volume de comercialização, qualquer variação desta quantia pode influenciar na alteração do preço;

- Ausência de preços observáveis: quando não há histórico ou disponibilidade de preços no mercado;

- Modelo de risco: diferenças observadas entre as respostas do modelo de avaliação e modelo teórico.

- Risco privado: inerente ao ambiente ou à própria companhia avaliada.

Sendo identificadas estas limitações, os resultados encontrados através da abordagem das opções reais podem divergir das respostas teóricas. De toda forma, as opções reais conduzem as melhores tomadas de decisão do que as abordagens tradicionais.

Com o aumento do uso destes modelos, melhores aplicações e mais sofisticadas análises serão possíveis através de informações mais robustas provenientes do mercado.

As opções reais estão presentes em boa parte das decisões de negócio e tendem a aparecer de forma variada. O grande desafio de se considerar a abordagem das opções nas estratégias está na capacidade de identificar as variadas formas de opções que se possui, separando-as umas das outras e decidindo-se qual é a de maior valor.

\section{ESTUDO DE CASO}

O projeto de investimento avaliado nesse estudo pela TOR foi o caso real implementado na empresa Thyssen Krupp, por meio de uma parceria entre a Universidade Federal do $\mathrm{ABC}$ e a empresa, intitulado "Sistema automatizado para medição e monitoramento de desgaste de brocas de metal duro baseado na análise de imagens".

\subsection{O PROJETO AVALIADO E A INDÚSTRIA 4.0}

O objetivo deste projeto era o desenvolvimento de um sistema de medição automatizado baseado na análise de imagens, que podia inspecionar e monitorar o desgaste de brocas, afim de evitar quebras de ferramenta e assim causar danos ao produto, e consequentemente, o seu descarte e custos ao fabricante. Outro ponto a se considerar como objetivo deste projeto era a melhoria na eficiência no tempo de produção e o melhor uso dos recursos para tal.

A escolha por esse caso se deu pela sua aderência aos conceitos de Indústria 4.0 apresentados. O cenário de análise correlaciona-se com o ambiente de transformação digital atual e sua capacidade de expansão para projetos encadeados no futuro.

Para realizar esta avaliação de aderência, listou-se seis itens que apontam as características ou objetivos específicos do projeto e o que se faz necessário para cumprilo.

Quadro 1- Lista de características do projeto isolado.
\begin{tabular}{|c|l|}
\hline Item & \multicolumn{1}{c|}{ Características ou objetivos específicos } \\
\hline 1 & $\begin{array}{l}\text { Desenvolver arquitetura para a integração do sistema no processo de fabricação (Esquemas de } \\
\text { ilustração para a construção do sistema); }\end{array}$ \\
\hline
\end{tabular}


A Teoria de Opções Reais na Gestão de Investimentos na Indústria 4.0: um Estudo de Caso

\begin{tabular}{|c|l|}
\hline 2 & $\begin{array}{l}\text { Desenvolver o software para aquisição das imagens e processamento para a medição do } \\
\text { desgaste; }\end{array}$ \\
\hline 3 & $\begin{array}{l}\text { Implementar algoritmo que avalie a ferramenta em tempo real e aponte quando deve ser trocada } \\
\text { (Monitoramento do desgaste a fim de maximizar a vida útil da ferramenta, além de indicar } \\
\text { ponto ótimo de troca); }\end{array}$ \\
\hline 4 & $\begin{array}{l}\text { Armazenar os resultados de medição e monitoramento da vida útil da ferramenta (As imagens e } \\
\text { medições serão armazenadas através de um banco de dados); }\end{array}$ \\
\hline 5 & $\begin{array}{l}\text { Avaliar o uso dos resultados de medição para ampliação da implementação dos conceitos da } \\
\text { indústria 4.0 no processo de monitoramento do processo fabricação; }\end{array}$ \\
\hline 6 & Desenvolvimento do protótipo final para avaliação prática no chão de fábrica. \\
\hline
\end{tabular}

A análise foi feita de forma qualitativa, identificando dentro dos objetivos específicos propostos em níveis de $0 \%, 25 \%, 50 \%, 75 \%$ e 100\% de aderência aos conceitos de Indústria 4.0.

Nesta escala é considerado $0 \%$ quando objetivo específico do projeto não tem qualquer grau correlacionado ao conceito de Indústria 4.0 avaliado. Para $100 \%$ é aderência total do objetivo específico ao conceito mapeado. E a variação dentro da escala é uma adequação intermediária aos conceitos aplicados na Indústria 4.0. O Quadro 2 apresenta o resultado da avaliação.

Quadro 2 - Aderência do projeto à Indústria 4.0

\begin{tabular}{|c|c|c|c|c|c|c|c|c|}
\hline \multirow[b]{2}{*}{ Item } & \multirow[b]{2}{*}{ Objetivos Específicos } & \multicolumn{7}{|c|}{ Conceitos da Indústria 4.0} \\
\hline & & 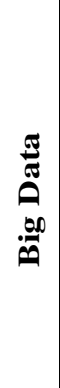 & 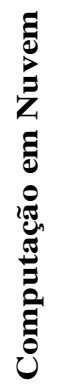 & $\stackrel{?}{\varrho}$ & 苞 & $\frac{\tilde{U}}{U}$ & 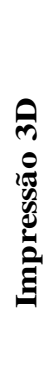 & 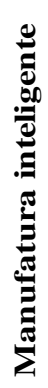 \\
\hline 1 & $\begin{array}{c}\text { Desenvolver arquitetura para a integração do sistema no processo } \\
\text { de fabricação (Esquemas de ilustração para a construção do } \\
\text { sistema); }\end{array}$ & 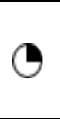 & & & & & & \\
\hline 2 & $\begin{array}{l}\text { Desenvolver o software para aquisição das imagens e } \\
\text { processamento para a medição do desgaste; }\end{array}$ & & & & & & & \\
\hline 3 & $\begin{array}{c}\text { Implementar algoritmo que avalie a ferramenta em tempo real e } \\
\text { aponte quando deve ser trocada (Monitoramento do desgaste a } \\
\text { fim de maximizar a vida útil da ferramenta, além de indicar ponto } \\
\text { ótimo de troca); }\end{array}$ & & & & & & & \\
\hline 4 & $\begin{array}{c}\text { Armazenar os resultados de medição e monitoramento da vida útil } \\
\text { da ferramenta (As imagens e medições serão armazenadas através } \\
\text { de um banco de dados); }\end{array}$ & & & & & & & \\
\hline 5 & $\begin{array}{l}\text { Avaliar o uso dos resultados de medição para ampliação da } \\
\text { implementação dos conceitos da indústria } 4.0 \text { no processo de } \\
\text { monitoramento do processo fabricação; }\end{array}$ & & & $\mathbf{M}$ & 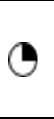 & & & \\
\hline 6 & $\begin{array}{c}\text { Desenvolvimento do protótipo final para avaliação prática no chão } \\
\text { de fábrica. }\end{array}$ & & & & & & & \\
\hline
\end{tabular}

Fonte: Elaborado pelos autores 


\section{A Teoria de Opções Reais na Gestão de Investimentos}

na Indústria 4.0: um Estudo de Caso

É possível identificar que os objetivos propostos no projeto "Sistema automatizado para medição e monitoramento de desgaste de brocas de metal duro baseado na análise de imagens", possuem alto grau de aderência aos conceitos de CPS, Big Data e Manufatura Inteligente, sendo que estes dois últimos aparecem em todos os objetivos identificados. Por se tratar de um projeto que contempla análise preditiva a partir do uso de dados a características inerentes ao projeto estão mais próximos aos conceitos identificados.

Os outros conceitos como o Impressão 3D, IoS estão menos presentes ao Caso em análise. Por se tratar de um projeto que não contempla o uso direto para serviços e clientes finais, bem como a criação de um protótipo de simulação para objetivos diversos (redução de custos, testes prévios, etc.).

Desta maneira, é possível avaliar que o projeto está totalmente inserido dentro dos conceitos propostos no cenário da Indústria 4.0.

Para elaboração da análise do caso em questão sob a ótica de Opções reais, são realizados em quatro etapas, iniciando pelo cálculo tradicional de análise de investimentos em projetos, em seguida modelagem das árvores de eventos, passando para a incorporação da flexibilidade gerencial e, assim construir uma árvore de decisões, finalizando com a análise de opções reais de expansão para o caso apresentado.

\subsubsection{Análise Padrão Do Valor Presente - Etapa 1}

Primeiramente são identificados detalhadamente os investimentos previstos para o projeto "Sistema automatizado para medição e monitoramento de desgaste de brocas de metal duro baseado na análise de imagens", apresentados na Tabela 2.

Tabela 2 - Investimentos no projeto "Sistema automatizado para medição e monitoramento de desgaste de brocas de metal duro baseado na análise de imagens"

\begin{tabular}{l|rr}
\hline \multicolumn{1}{c|}{ Materiais } & \multicolumn{2}{c}{ Valores } \\
\hline Câmera Industrial (1 unidade) & $\mathrm{R} \$$ & $11.210,00$ \\
\hline Desktop Core I7 & $\mathrm{R} \$$ & $4.925,00$ \\
\hline Software para processamento de imagem & $\mathrm{R} \$$ & 740,00 \\
\hline Licença para banco de dados & $\mathrm{R} \$$ & 500,00 \\
\hline Placa aquisição de dados & $\mathrm{R} \$$ & 250,00 \\
\hline Cabos & $\mathrm{R} \$$ & 150,00 \\
\hline Interface RS-232 & $\mathrm{R} \$$ & 155,00 \\
\hline Conectores elétricos & $\mathrm{R} \$$ & 100,00 \\
\hline Materiais para acabamento elétrico & $\mathrm{R} \$$ & 150,00 \\
\hline Passa cabo industrial & $\mathrm{R} \$$ & 350,00 \\
\hline Sistema de iluminação a LED & $\mathrm{R} \$$ & 870,00 \\
\hline Despesas gerais & $\mathrm{R} \$$ & $27.100,00$ \\
\hline & $\mathrm{R} \$$ & $46.500,00$ \\
\hline
\end{tabular}

Fonte: Elaborado pelos autores

O tempo previsto para a finalização do projeto "Sistema automatizado para medição e monitoramento de desgaste de brocas de metal duro baseado na análise de imagens" é de 12 meses. Posteriormente existe a possibilidade do desencadeamento de 
A Teoria de Opções Reais na Gestão de Investimentos na Indústria 4.0: um Estudo de Caso

novas aplicações na própria manufatura incorporar mais conceitos inerentes ao contexto da Indústria 4.0.

Para ilustrar essa possibilidade, na Figura 2 é apresentado um modelo de projetos encadeados que podem vir a serem desenvolvidos pela empresa para adotar as inovações tecnológicas no cenário da Era Digital.

Figura 2 - Projetos Encadeados de Indústria 4.0

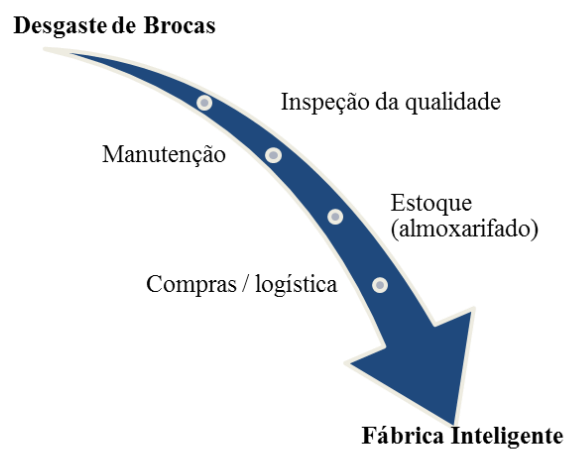

Fonte: Elaborado pelos autores

O modelo da Figura 2 ilustra que a partir de um projeto inicial para tratar o desgaste de brocas em um ponto do processo de fabricação na indústria de máquinas e equipamentos, possam surgir outras necessidades em forma de novos projetos que possam desencadear aplicações em todo o processo de fabricação da empresa.

Desta maneira poder-se-á transcender somente uma aplicação que busca diminuir quebras de ferramentas e redução de custos, para uma situação que visa utilizar diversas tecnologias em todo o processo, possibilitando alcançar a manufatura inteligente que proporcionará diferenciação competitiva para a empresa e seus clientes.

Para caracterizar os projetos propostos neste modelo de modo a aproximar da realidade é apresentado no Quadro 3 o projeto inicial que é objeto deste estudo de caso e os próximos cinco projetos desencadeados e suas características principais.

Quadro 3 - Caracterização dos Projetos Encadeados

\begin{tabular}{|c|l|l|}
\hline Passos & \multicolumn{1}{|c|}{ Projetos } & \multicolumn{1}{c|}{ Característica } \\
\hline 1 & $\begin{array}{l}\text { Sistema automatizado para medição } \\
\text { e monitoramento de desgaste de } \\
\text { brocas de metal duro baseado na } \\
\text { análise de imagens }\end{array}$ & $\begin{array}{l}\text { Desenvolvimento de um sistema de medição } \\
\text { automatizado baseado na análise de imagens para } \\
\text { inspeção do desgaste de brocas de metal duro, durante } \\
\text { o processo de furação em centro de usinagem, visando } \\
\text { à utilização de elementos do conceito de Indústria } 4.0 \\
\text { na fabricação de rolamentos de grande porte. }\end{array}$ \\
\hline 2 & $\begin{array}{l}\text { Inspeção de Qualidade } \\
\text { Sistema capaz de avaliar a condição da peça e suas } \\
\text { especificações técnicas. Realizar inspeção de qualidade } \\
\text { e gerar dados do processo de manufatura. }\end{array}$ \\
\hline 3 & Manutenção das máquinas & $\begin{array}{l}\text { Sistema para análises preditivas de manutenção nas } \\
\text { máquinas de usinagem e de inspeção de qualidade. }\end{array}$ \\
\hline
\end{tabular}


A Teoria de Opções Reais na Gestão de Investimentos na Indústria 4.0: um Estudo de Caso

\begin{tabular}{|c|l|l|}
\hline 4 & Estoque (almoxarifado) & $\begin{array}{l}\text { Sistema que conectado ao consumo de matéria prima } \\
\text { nas máquinas, permitindo liberação de produtos } \\
\text { acabados ou identificação de estoque de MP. }\end{array}$ \\
\hline 5 & Compras / logística & $\begin{array}{l}\text { Identifica a necessidade de aquisição de suprimentos de } \\
\text { forma antecipada, para otimizar recursos dentro da } \\
\text { fábrica. E a necessidade de transporte dos produtos } \\
\text { acabados }\end{array}$ \\
\hline 6 & $\begin{array}{l}\text { Processamento, armazenamento e e } \\
\text { análise de dados (BI) - Fábrica } \\
\text { Inteligente }\end{array}$ & $\begin{array}{l}\text { Agrupa todas as informações, disponibilizando para alta } \\
\text { gerência gráficos de performance das áreas comercial e } \\
\text { produtiva. }\end{array}$ \\
\hline
\end{tabular}

Fonte: Elaborado pelos autores

Após apresentação das características principais dos possíveis projetos a serem desenvolvidos no cenário da Indústria 4.0, foi elaborado de forma hipotética um modelo, na qual são identificados os possíveis investimentos e seus retornos para a empresa, apresentados na Tabela 3.

Tabela 3 - Investimentos dos projetos encadeados

\begin{tabular}{|c|c|c|c|c|c|c|}
\hline Passo & Projetos & \multicolumn{2}{|c|}{ Investimento } & \multicolumn{2}{|c|}{$\begin{array}{l}\text { Retorno } \\
\text { Mensal }\end{array}$} & $\begin{array}{c}\text { Retorno } \\
\text { Anual }\end{array}$ \\
\hline 1 & $\begin{array}{l}\text { Sistema automatizado para medição e } \\
\text { monitoramento de desgaste de brocas de } \\
\text { metal duro baseado na análise de imagens }\end{array}$ & $\mathrm{R} \$$ & $46.500,00$ & $\mathrm{R} \$$ & $2.212,50$ & $\mathrm{R} \$ 26.550,00$ \\
\hline 2 & Inspeção da Qualidade & $\mathrm{R} \$$ & $55.000,00$ & $\mathrm{R} \$$ & $2.750,00$ & $\mathrm{R} \$ 33.000,00$ \\
\hline 3 & Manutenção das máquinas & $\mathrm{R} \$$ & $60.000,00$ & $\mathrm{R} \$$ & $3.000,00$ & $\mathrm{R} \$ 36.000,00$ \\
\hline 4 & Estoque (almoxarifado) & $\mathrm{R} \$$ & $65.000,00$ & $\mathrm{R} \$$ & $3.250,00$ & $\mathrm{R} \$ 39.000,00$ \\
\hline 5 & Compras e Logística & $\mathrm{R} \$$ & $70.000,00$ & $\mathrm{R} \$$ & $3.500,00$ & $\mathrm{R} \$ 42.000,00$ \\
\hline \multirow[t]{2}{*}{6} & $\begin{array}{l}\text { Processamento, armazenamento e análise de } \\
\text { dados (BI) }\end{array}$ & $\mathrm{R} \$$ & $80.000,00$ & $\mathrm{R} \$$ & $4.000,00$ & $\mathrm{R} \$ 48.000,00$ \\
\hline & Total & $\mathrm{R} \$$ & $376.500,00$ & $\mathrm{R} \$$ & $18.712,50$ & $\mathrm{R} \$ 24.550,00$ \\
\hline
\end{tabular}

Fonte: Elaborado pelos autores

Os valores de retornos mensais apresentados levam em conta possíveis reduções de custo e ganhos produtivos. Para os projetos de número 2 ao 6 aplicam-se valores hipotéticos destes retornos mensais. Já o Projeto "Sistema automatizado para medição e monitoramento de desgaste de brocas de metal duro baseado na análise de imagens" possui valores reais projetados.

Assim, o primeiro passo para o processo de avaliação de Opções Reais é o cálculo do Valor Presente Líquido para o projeto. No caso em questão, inicialmente parte-se da análise do projeto "Sistema automatizado para medição e monitoramento de desgaste de brocas de metal duro baseado na análise de imagens" de forma isolada.

Dentre estas, a prevenção de quebra de brocas e pontas de inserto representam mais de dois terços das expectativas de redução de custos deste projeto. Esta prevenção de quebras e trocas é feita através da análise das imagens obtidas que identifica o ponto de desgaste máximo antes de ocorrer uma quebra. Outra vantagem é a de que a aplicação de análise preditiva neste processo de usinagem reduzirá o tempo de setup. 
As oportunidades de redução de custo mapeadas para o projeto "Sistema automatizado para medição e monitoramento de desgaste de brocas de metal duro baseado na análise de imagens" são apresentadas na Tabela 4.

Tabela 4 - Possíveis reduções de custos para o projeto

\begin{tabular}{|c|c|c|c|c|}
\hline Descrição & Justificativa & Qtde/ano & $\begin{array}{l}\text { Preço } \\
\text { Unitário }\end{array}$ & $\begin{array}{l}\text { Reduções } \\
\text { Totais }\end{array}$ \\
\hline $\begin{array}{ll}\text { Brocas } & \text { de } \\
\text { Usinagem } & \\
\end{array}$ & $\begin{array}{l}\text { Prevenção de quebra durante usinagem, } \\
\text { por determinação de tempo de troca }\end{array}$ & 3 peças & $\mathrm{R} \$ 2.850,00$ & $\mathrm{R} \$ \quad 8.550,00$ \\
\hline $\begin{array}{l}\text { Pontas } \\
\text { inserto }\end{array}$ & $\begin{array}{l}\text { Prevenção de quebra durante usinagem, } \\
\text { por análise de tempo de troca. Redução } \\
30 \% \text { de perdas }\end{array}$ & 350 peças & 30,00 & $\mathrm{R} \$ 10.500,00$ \\
\hline \multirow[t]{2}{*}{$\begin{array}{l}\text { Tempo de } \\
\text { processo }\end{array}$} & $\begin{array}{l}\text { Redução do tempo de operação, } \\
\text { possibilidade de trabalhar com altos } \\
\text { parâmetros de análise. }\end{array}$ & $\begin{array}{l}300 \\
\text { minutos }\end{array}$ & 25,00 & $\mathrm{R} \$ \quad 7.500,00$ \\
\hline & & & Total & $\mathrm{R} \$ 26.550,00$ \\
\hline
\end{tabular}

Fonte: Elaboração Própria.

Os dados permitem concluir que a implantação deste projeto irá possibilitar uma redução de custo no valor de $\mathrm{R} \$ 26.550,00$ ao ano. Nesse estudo, foi adotada uma taxa de depreciação de $5 \%$ a.a., conforme identificado em RFB (1999).

Considerando a taxa de depreciação, o valor do investimento no projeto e os retornos esperados em sua implementação, aplicando-se o modelo chega-se aos resultados apresentados na Tabela 5.

Tabela 5 - Fluxo de Caixa para o Projeto

\begin{tabular}{c|c|c}
\hline Ano & Atividades & Fluxo de Caixa (R\$) \\
\hline Ano 1 & Investimento & $-\mathrm{R} \$ 46.500,00$ \\
\hline Ano 2 & Retorno - depreciação & $\mathrm{R} \$ 25.222,50$ \\
\hline Ano 3 & Retorno - depreciação & $\mathrm{R} \$ 23.961,38$ \\
\hline Ano 4 & Retorno - depreciação & $\mathrm{R} \$ 22.763,31$ \\
\hline Ano 5 & Retorno - depreciação & $\mathrm{R} \$ 21.625,14$ \\
\hline Ano 6 & Retorno - depreciação & $\mathrm{R} \$ 20.543,88$
\end{tabular}

Fonte: Elaborado pelos autores

Depois de determinado o fluxo de caixa, calcula-se o Valor Presente Líquido para o projeto considerando três cenários diferentes, levando em consideração diferentes taxas de atratividade, que é a taxa de juros que representa o mínimo que um investidor se propõe a ganhar quando faz um investimento.

O primeiro é um cenário otimista que leva em consideração uma taxa de atratividade de $7 \%$ a.a. O segundo cenário é moderado, com taxa de atratividade em $10 \%$ a.a. Por fim um cenário mais pessimista, o qual o Brasil atravessou nos anos entre 2014 e 2016, com uma taxa de atratividade de $13 \%$ a.a.

Os resultados obtidos no cálculo do VPL são apresentados na Tabela 6, com nome dado ao projeto de "Projeto 1", por se tratar do primeiro projeto a ser implementado, e que será utilizado até o final da análise. 
A Teoria de Opções Reais na Gestão de Investimentos na Indústria 4.0: um Estudo de Caso

Tabela 6 - Valor Presente Líquido para o projeto

\begin{tabular}{c|c}
\hline VPL & Projeto 1 \\
\hline VPL - Otimista & $\mathrm{R} \$ 62.034,31$ \\
\hline VPL - Moderado & $\mathrm{R} \$ 51.868,71$ \\
\hline VPL Pessimista & $\mathrm{R} \$ 43.292,88$ \\
\hline
\end{tabular}

Fonte: Elaborado pelos autores.

A Figura 3 mostra a evolução do fluxo de caixa para o Projeto 1. Possibilita identificar que a depreciação irá ao longo do tempo diminuir os ganhos obtidos através da implementação deste projeto. O tempo de depreciação em análise leva em consideração o período de incorporação de novos projetos, que será apresentado em seguida.

Figura 3 - Fluxo de Caixa para o Projeto 1.

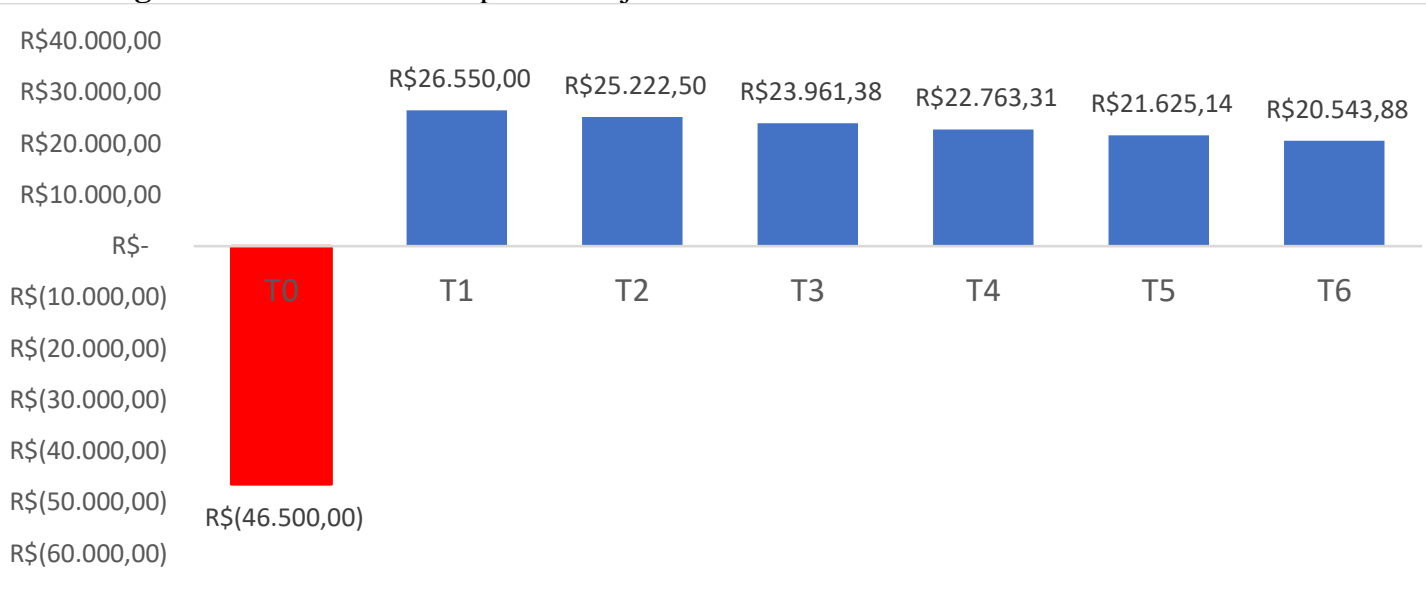

Fonte: Elaborado pelos autores

Quando levado em conta os investimentos na implementação de todos os projetos encadeados, como está descrito na Tabela 3, bem como seus retornos esperados, obtémse o fluxo de caixa apresentado na Tabela 7 ao longo do período de 6 anos. Considerando que os projetos listados serão implantados um por ano, durante o período citado.

Tabela 7 - Fluxo de Caixa considerando os projetos encadeados

\begin{tabular}{c|c}
\hline Período & Fluxo de Caixa \\
\hline $\mathrm{T} 0$ & $-\mathrm{R} \$ 46.500,00$ \\
\hline $\mathrm{T} 1$ & $-\mathrm{R} \$ 74.950,00$ \\
\hline $\mathrm{T} 2$ & $-\mathrm{R} \$ 79.727,50$ \\
\hline $\mathrm{T} 3$ & $-\mathrm{R} \$ 56.266,13$ \\
\hline $\mathrm{T} 4$ & $-\mathrm{R} \$ 8.227,82$ \\
\hline $\mathrm{T} 5$ & $\mathrm{R} \$ 53.658,57$ \\
\hline $\mathrm{T} 6$ & $\mathrm{R} \$ 261.450,64$ \\
\hline
\end{tabular}

Fonte: Elaborado pelos autores

Após a obtenção dos resultados do fluxo de caixa que considera os seis projetos propostos é calculado o valor presente líquido para os cenários otimista, moderado e pessimista. São assumidos os mesmos parâmetros de taxa de atratividade e depreciação utilizados no cálculo do Projeto 1 . Os resultados são apresentados na Tabela 8. 
A Teoria de Opções Reais na Gestão de Investimentos na Indústria 4.0: um Estudo de Caso

Tabela 8 - Análise do VPL para os projetos encadeados

\begin{tabular}{c|c}
\hline VPL & VPL Total \\
\hline VPL - Otimista & $-\mathrm{R} \$ 24.221,75$ \\
\hline VPL - Moderado & $-\mathrm{R} \$ 43.200,29$ \\
\hline VPL Pessimista & $-\mathrm{R} \$ 57.171,66$ \\
\hline
\end{tabular}

Fonte: Elaborado pelos autores.

A Figura 4 abaixo mostra a evolução do fluxo de caixa para todos os projetos.

Figura 1 - Fluxo de Caixa para todos os projetos encadeados

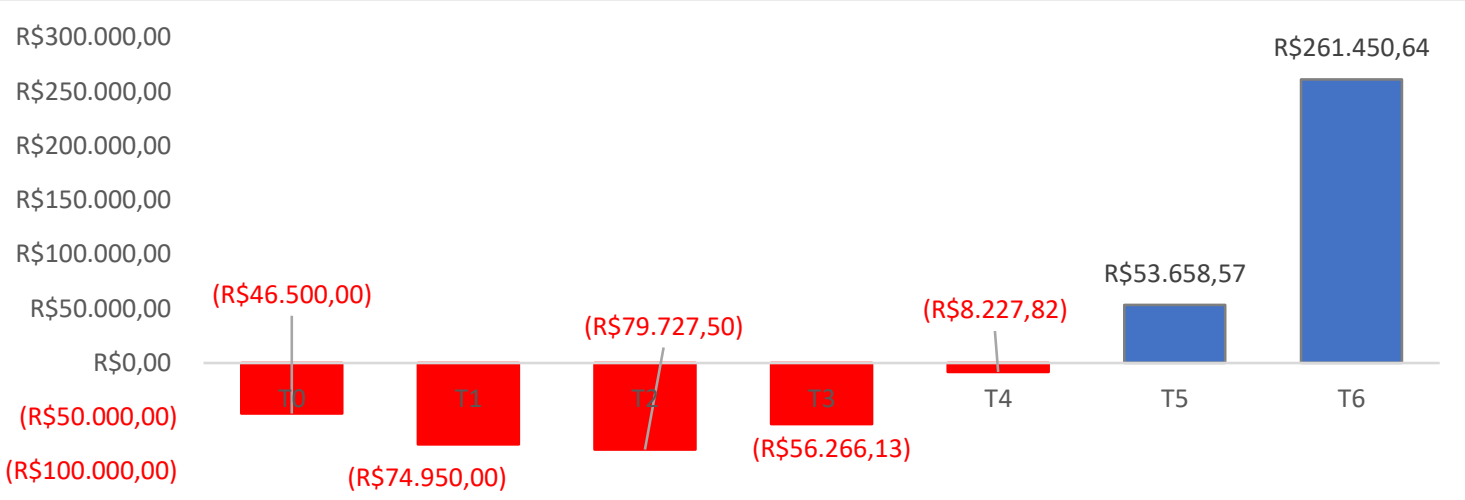

Fonte: Elaborado pelos autores.

É possível identificar no fluxo de caixa que o fluxo de caixa será negativo durante os quatro primeiros anos de investimentos e retornos no Projeto 1. A partir do quinto ano os retornos serão maiores do que os investimentos.

\subsubsection{Análise Monte Carlo - Etapa 2}

O segundo passo da avaliação de opções reais é a construção de uma árvore de eventos, baseada em um conjunto de incertezas combinadas que influenciam a volatilidade do projeto.

Baseado nas expectativas de receitas apresentadas na seção anterior e considerando a demanda constante dentro do histórico da empresa para o setor de máquinas e equipamentos, realizaram-se simulações em planilha de Excel para cálculo da volatilidade dos projetos em análise.

A volatilidade do projeto é o desvio padrão das variações percentuais do valor presente do projeto ao longo dos anos, conforme a abordagem consolidada da incerteza descrita por (COPELAND, 2002), ou seja, a taxa de retorno do projeto, calculada por:

$$
\begin{aligned}
& Z=\ln \left(\frac{V P_{1}+F C_{1}}{V P_{0}}\right), \text { onde: } \\
& V P_{0}=\left\{\sum_{t=1}^{T} F C_{t} /(1+T R)^{t}\right\} \\
& V P_{1}=\left\{\sum_{t=2}^{T} F C_{t} /(1+T R)^{t-1}\right\}
\end{aligned}
$$

Foi considerado $\mathrm{Z}$ como a distribuição do valor $\mathrm{VP}_{1}$ é o Valor Presente do projeto no tempo, $\mathrm{VP}_{0}$ é o valor presente inicial.

Durante a simulação de Monte Carlo, a distribuição do valor Z é obtida mantendose constante o valor de $\mathrm{VP}_{0}$ e deixando $\mathrm{VP}_{1}$ e $\mathrm{FC}_{\mathrm{t}}$ variarem com a incerteza introduzida 
como hipóteses. Para esta análise foram realizadas dez mil tentativas, considerando a distribuição da taxa de retorno com um comportamento aproximado da normal, como ilustrado na Figura 5.

O retorno obtido através das consultas estatísticas para o desvio padrão da taxa de retorno é a volatilidade do projeto, sendo ela no valor de $4,48 \%$.

Figura 2 - Distribuição de frequência das receitas anuais esperadas

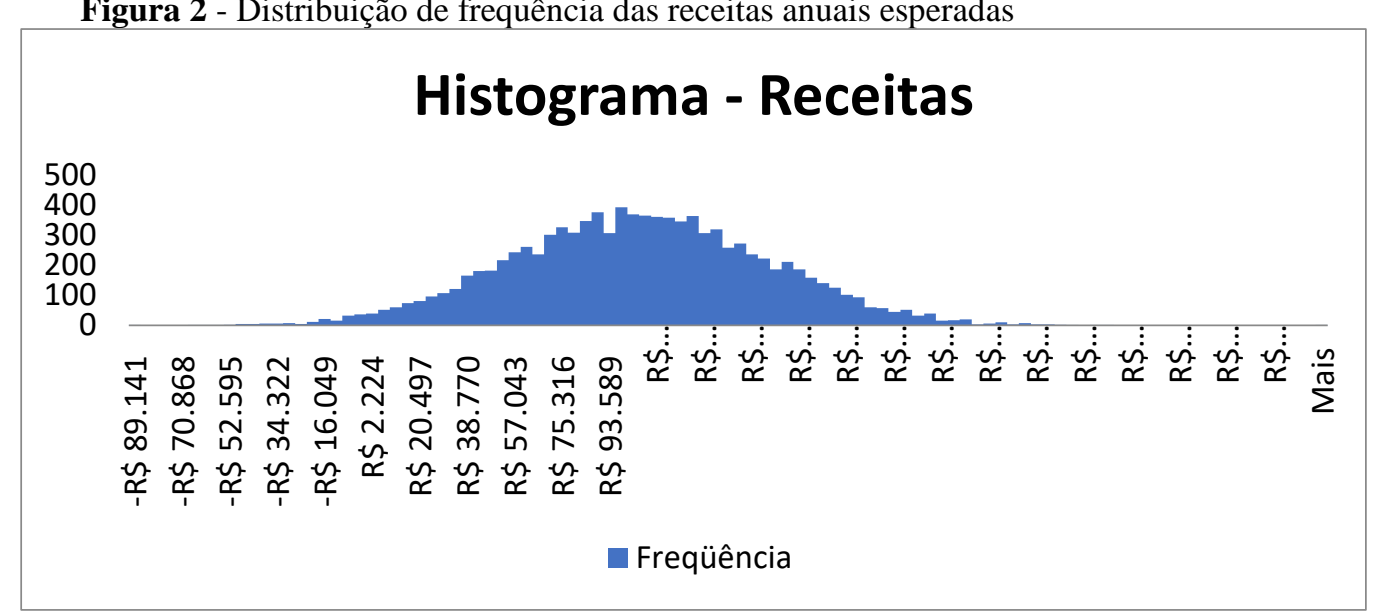

Fonte: Elaborado pelos autores.

O grau de volatilidade do projeto se mostrou baixo, o que significa que com 95,5\% de chance de que as receitas previstas para os projetos encadeados em estudo estejam dentro de uma faixa prevista de $\mathrm{R} \$ 20.497$ e $\mathrm{R} \$ 203.227$.

Após a obtenção destes resultados é construída a Árvore de Eventos que considera os projetos encadeados.

A Árvore de Eventos segundo Minardi (2004) divide um projeto que envolve investimentos em passos para que se possa analisar os riscos e incertezas que implicam nas etapas seguintes. Desta maneira busca-se antecipar decisões gerenciais que devam ser tomadas em virtudes de mudanças nas condições do mercado.

A construção de uma árvore de eventos para este estudo de caso implica em avaliar os investimentos que podem ser realizados nos projetos de forma encadeada na busca pela implantação dos conceitos de Indústria 4.0 na empresa em questão e assim alcançar diferenciação competitiva.

Além disso, a Árvore de Eventos se torna uma ferramenta de grande valia para a empresa no momento que se limita os riscos de fracasso no momento do investimento, ao substituir um momento único que poderia ser feito o investimento em todos os seis projetos encadeados, passando para uma distribuição desses investimentos ao longo do tempo e decidindo conforme surjam novas informações.

Na Tabela 9 é apresentada a Árvore de Eventos para este estudo de caso. No qual são identificados oito períodos de tempo, partindo de T0 para T7. Para cada período são inseridos valores relacionados ao início de um projeto, em que há investimento, portanto uma saída do caixa, ou de um valor de retorno do projeto em forma de receita para empresa. Finalizando com a visão do Fluxo de Caixa, que apresenta a somatória dos eventos no período com os fluxos dos projetos que já estejam iniciados. 
Heidrich, Morais e Facó (2020)

A Teoria de Opções Reais na Gestão de Investimentos

na Indústria 4.0: um Estudo de Caso

Tabela 9 - Árvore de Eventos dos Projetos Encadeados

\begin{tabular}{c|l|l|l|l|l|l|c}
\hline Período & Projeto 1 & Projeto 2 & Projeto 3 & Projeto 4 & Projeto 5 & Projeto 6 & Fluxo de Caixa \\
\hline \multirow{2}{*}{$\mathrm{T} 0$} & $-\mathrm{R} \$$ & & & & & & $-\mathrm{R} \$$ \\
& 46.500 & & & & & & 46.500 \\
\hline \multirow{2}{*}{$\mathrm{T} 1$} & $\mathrm{R} \$$ & $-\mathrm{R} \$$ & & & & & $-\mathrm{R} \$$ \\
& 26.550 & 55.000 & & & & & 74.950 \\
\hline \multirow{2}{*}{$\mathrm{T} 2$} & $\mathrm{R} \$$ & $\mathrm{R} \$$ & $-\mathrm{R} \$$ & & & & $-\mathrm{R} \$$ \\
& 25.223 & 30.000 & 60.000 & & & & 79.728 \\
\hline \multirow{2}{*}{$\mathrm{T} 3$} & $\mathrm{R} \$$ & $\mathrm{R} \$$ & $\mathrm{R} \$$ & $-\mathrm{R} \$$ & & & $-\mathrm{R} \$$ \\
& 23.961 & 28.500 & 36.000 & 65.000 & & & 56.266 \\
\hline \multirow{2}{*}{$\mathrm{T} 4$} & $\mathrm{R} \$$ & $\mathrm{R} \$$ & $\mathrm{R} \$$ & $\mathrm{R} \$$ & $-\mathrm{R} \$$ & & $-\mathrm{R} \$$ \\
& 22.763 & 27.075 & 34.200 & 39.000 & 75.000 & & 8.228 \\
\hline \multirow{2}{*}{$\mathrm{T} 5$} & $\mathrm{R} \$$ & $\mathrm{R} \$$ & $\mathrm{R} \$$ & $\mathrm{R} \$$ & $\mathrm{R} \$$ & $-\mathrm{R} \$$ & $\mathrm{R} \$$ \\
& 21.625 & 25.721 & 32.490 & 37.050 & 45.000 & 100.000 & 53.659 \\
\hline \multirow{2}{*}{$\mathrm{T} 6$} & $\mathrm{R} \$$ & $\mathrm{R} \$$ & $\mathrm{R} \$$ & $\mathrm{R} \$$ & $\mathrm{R} \$$ & $\mathrm{R} \$$ & $\mathrm{R} \$$ \\
& 20.544 & 24.435 & 30.866 & 35.198 & 42.750 & 54.000 & 261.451 \\
\hline \multirow{2}{*}{$\mathrm{T} 7$} & $\mathrm{R} \$$ & $\mathrm{R} \$$ & $\mathrm{R} \$$ & $\mathrm{R} \$$ & $\mathrm{R} \$$ & $\mathrm{R} \$$ & $\mathrm{R} \$$ \\
& 19.517 & 23.213 & 29.322 & 33.438 & 40.613 & 51.300 & 458.853 \\
\hline
\end{tabular}

Fonte: Elaborado pelos autores.

As árvores de eventos modelam o conjunto de valores que o ativo subjacente sujeito a risco pode assumir ao longo do tempo, de acordo com Copeland e Antikarov (2002). Para cada período de tempo T foi considerado uma depreciação nos equipamentos e software no valor de $5 \%$.

Os resultados obtidos identificam os investimentos realizados ao longo do tempo e identificando as possíveis receitas advindas dos projetos já implantados anteriormente descontado a depreciação. Após a construção da Árvore de Eventos o próximo passo em opções reais é a construção da Árvore de decisão.

\subsection{3 Árvore De Decisão - Etapa 3}

O terceiro passo no processo de análise de opções reais para estimativa do valor de um projeto é a construção das árvores de decisões gerenciais. Estas decisões são representadas pelos nós das árvores de eventos. Nas árvores de decisão identificam-se os retornos das decisões ótimas, condicionadas aos eventos apresentados. Portanto, seus retornos são os que resultariam da opção, ou opções, conforme Copeland e Antikarov (2002).

Para este estudo de caso são tomadas duas formas de construções de árvores de decisão, a saber: Projeto Isolado ("Sistema automatizado para medição e monitoramento de desgaste de brocas de metal duro baseado na análise de imagens") e a proposta dos Projetos Encadeados.

A avaliação é feita de trás para frente e se inicia pela última coluna da árvore de decisão. Assim, no último período, calcula-se:

Valor da Opção Real = VP calculado na árvore de eventos - preço de exercício da opção.

Se o valor da opção for maior que zero, a opção de expansão deve ser exercida. Caso contrário, a opção não deve ser exercida, e o seu valor é zero.

$\mathrm{Na}$ Tabela 10 são apresentados os parâmetros de análise do Projeto Isolado para os três cenários (Otimista, Moderado e Pessimista), bem como o Valor da Opção encontrada. 
Heidrich, Morais e Facó (2020)

A Teoria de Opções Reais na Gestão de Investimentos na Indústria 4.0: um Estudo de Caso

Tabela 10 - Parâmetros do Projeto Isolado

\begin{tabular}{l|c|c|c}
\multicolumn{1}{c|}{ Parâmetros } & Otimista & Moderado & Pessimista \\
\hline Valor Presente Líquido & $\mathrm{R} \$ 62.034,31$ & $\mathrm{R} \$ 60.973,39$ & $\mathrm{R} \$ 43.292,88$ \\
\hline Probabilidade de Sucesso & 1,5 & 1,3 & 1,2 \\
\hline Probabilidade de Fracasso & 0,9 & 0,8 & 0,7 \\
\hline Taxa de Atratividade & $7 \%$ & $10 \%$ & $13 \%$ \\
\hline Investimento & $\mathrm{R} \$ 46.500,00$ & $\mathrm{R} \$ 46.500,00$ & $\mathrm{R} \$$ \\
\hline Espaço de Expansão & $100 \%$ & $75 \%$ & 500,00 \\
\hline Tempo de maturidade & 1 & 1 & 1 \\
\hline Etapas de implementação & 6 & 6 & 6 \\
\hline Valor da Opção & $\mathrm{R} \$ 18.540,00$ & $\mathrm{R} \$ 2.540,00$ & $\mathrm{R} \$$ \\
\hline
\end{tabular}

Fonte: Elaborado pelos autores.

Para as análises a seguir, a tomada de decisão é feita da seguinte maneira:

$$
V O R=\operatorname{Max}[S-X ; 0]
$$

Considerando, VOR - Valor da Opção Real e Max [S-X;0] o valor da opção de compra ao fim do prazo. No caso de S-X for o maior valor, a opção de expansão deve ser exercida, no caso contrário, aconselha-se aguardar um melhor momento de investimento.

A Figura 6 apresenta o resultado da análise do cenário otimista.

Figura 3 - Árvore Binomial de decisão - Projeto Isolado: Cenário Otimista

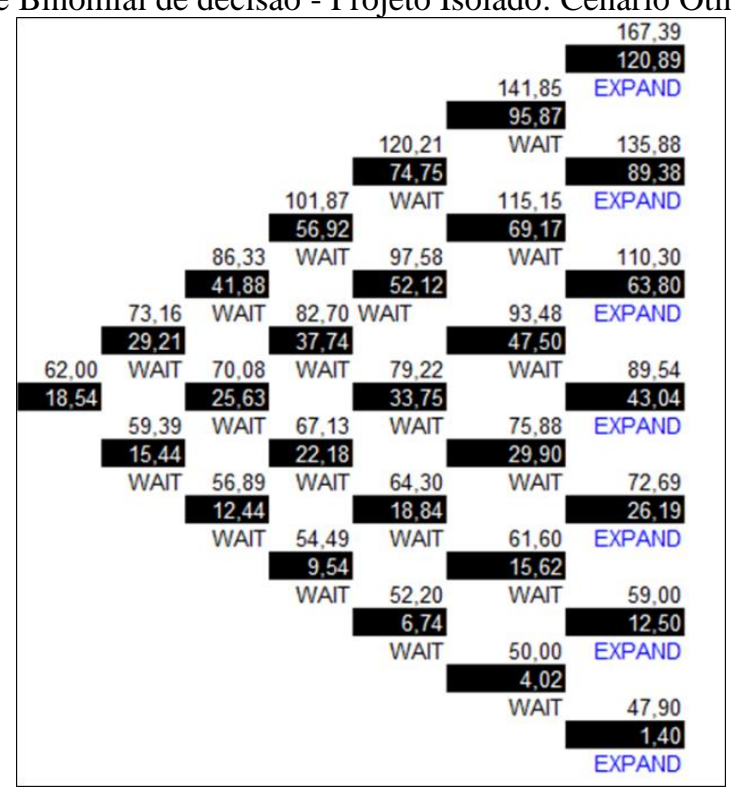

Fonte: Elaborado pelos autores.

No cenário otimista observa-se que para uma opção americana, na qual é possível exercer a opção a qualquer momento antes ou até a expiração da mesma, os primeiros nós da árvore binomial indicam que a opção de esperar ("Wait") é maior do que no último período que indica o seu vencimento.

Portanto, a flexibilidade está em aguardar até o último passo para maximizar os ganhos. A seguir, a Figura 7 apresenta o resultado da análise do cenário moderado. 
A Teoria de Opções Reais na Gestão de Investimentos na Indústria 4.0: um Estudo de Caso

Figura 4 - Árvore Binomial de decisão - Projeto Isolado: Cenário Moderado

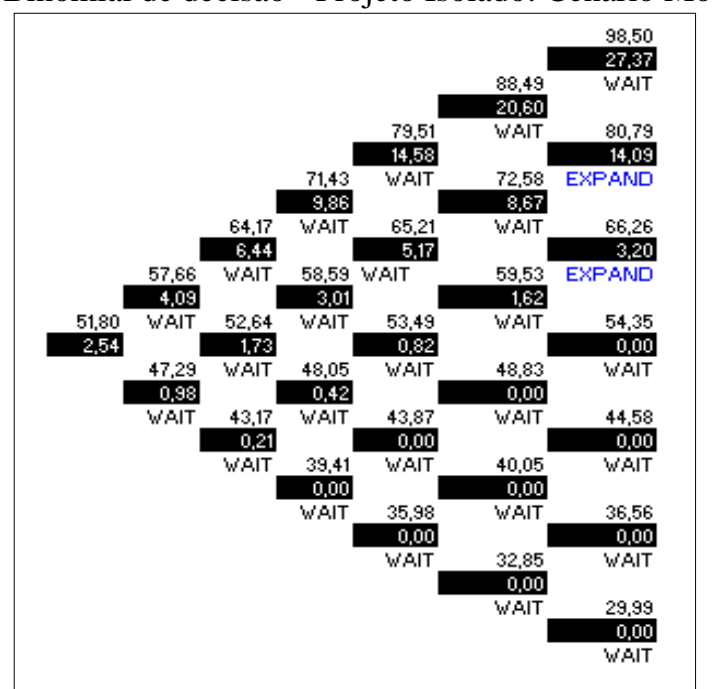

Fonte: Elaborado pelos autores.

No cenário moderado observa-se que para uma opção americana, novamente os primeiros nós da árvore binomial indicam que a opção de esperar ("Wait") é maior do que no último período que indica o seu vencimento e a possibilidade de expansão ("Expand").

Portanto, a flexibilidade está em aguardar até o último passo para maximizar os ganhos, mas para este cenário há somente dois caminhos que indicam a expansão dentro das probabilidades simuladas. A seguir, a Figura 8 apresenta o resultado da análise do cenário pessimista.

Figura 5 - Árvore Binomial de decisão - Projeto Isolado: Cenário Pessimista

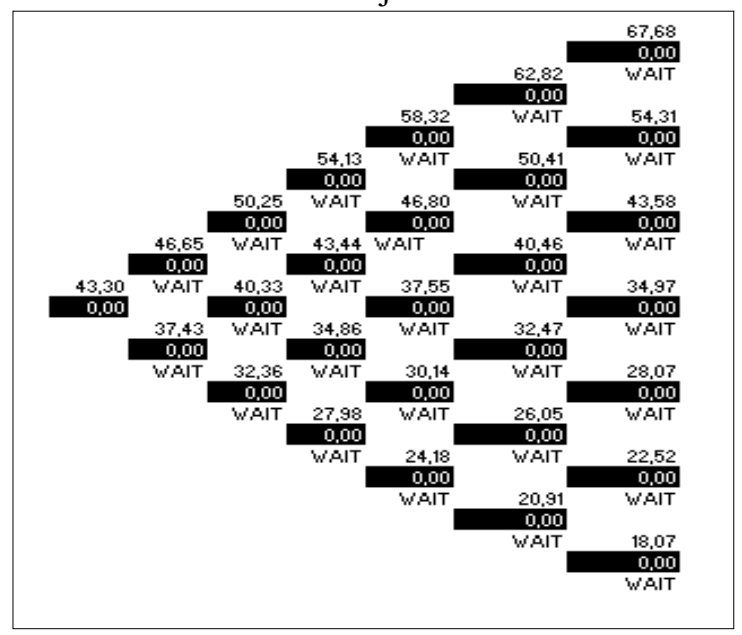

Fonte: Elaborado pelos autores.

No cenário pessimista observa-se que para uma opção americana, não deve ser exercida a opção de expansão ("Expand”). Portanto, a flexibilidade está em aguardar até um cenário melhor para que o investimento tenha um retorno mais adequado.

Em seguida, são apresentados os parâmetros de análise para os Projetos Encadeados nos três cenários (Otimista, Moderado e Pessimista), bem como o Valor da Opção encontrada. A Tabela 11 expõe os parâmetros de análise. 
Heidrich, Morais e Facó (2020)

A Teoria de Opções Reais na Gestão de Investimentos na Indústria 4.0: um Estudo de Caso

Tabela 11 - Parâmetros dos Projetos Encadeados

\begin{tabular}{l|c|c|c}
\hline \multicolumn{1}{c|}{ Parâmetros } & Otimista & Moderado & Pessimista \\
\hline Valor Presente Líquido & $\mathrm{R} \$ 242.834,94$ & $\mathrm{R} \$ 170.858,07$ & $\mathrm{R} \$ 115.430,47$ \\
\hline Probabilidade de Sucesso & 1,5 & 1,3 & 1,2 \\
\hline Probabilidade de Fracasso & 0,9 & 0,8 & 0,7 \\
\hline Taxa de Atratividade & $7 \%$ & $10 \%$ & $13 \%$ \\
\hline Investimento & $\mathrm{R} \$ 401.500,00$ & $\mathrm{R} \$ 401.500,00$ & $\mathrm{R} \$ 401.500,00$ \\
\hline Espaço de Expansão & $100 \%$ & $75 \%$ & $50 \%$ \\
\hline Tempo de maturidade & 7 & 7 & 7 \\
\hline \multicolumn{1}{c|}{ Etapas de implementação } & 7 & 7 & 7 \\
\hline \multicolumn{1}{c|}{ Valor da Opção } & $\mathrm{R} \$ 60.480,00$ & $\mathrm{R} \$ 12.040,00$ & $\mathrm{R} \$$ \\
\hline
\end{tabular}

Fonte: Elaborado pelos autores.

Desta maneira, a arvore binomial de decisão para o cenário otimista pode ser observada, por meio da Figura 9.

Figura 6 - Árvore Binomial de decisão - Projetos Encadeados: Cenário Otimista

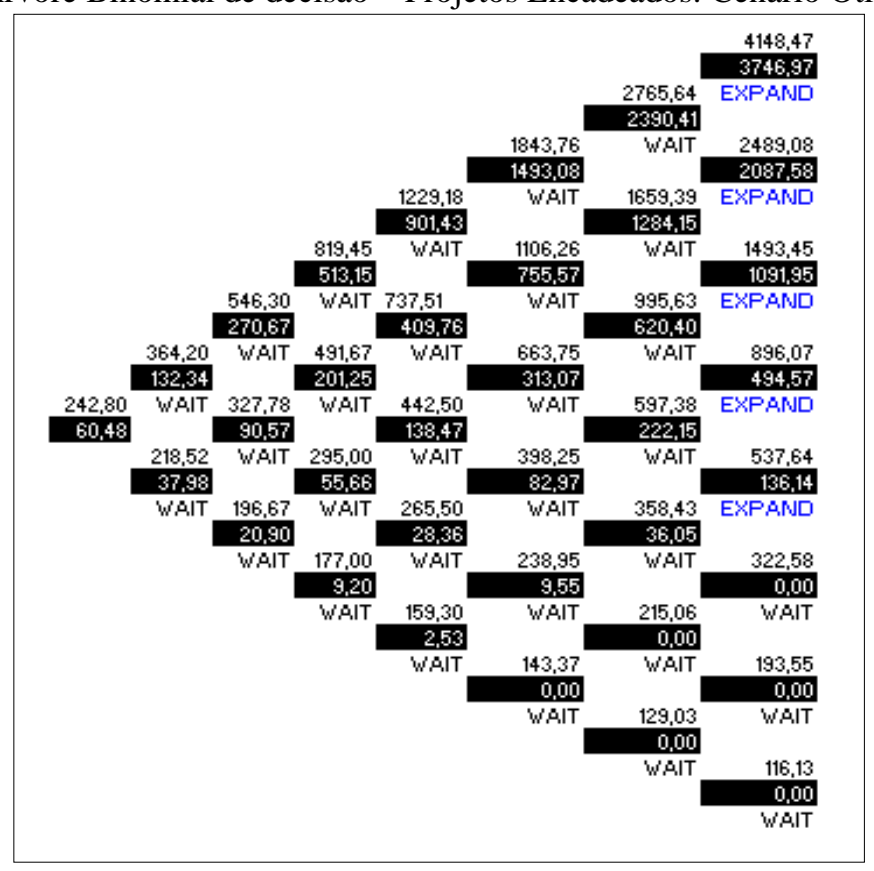

Fonte: Elaborado pelos autores.

No cenário otimista de Projetos Encadeados observa-se que para uma opção americana, os primeiros nós da árvore binomial indicam que a opção de esperar ("Wait") é maior do que no último período que indica o seu vencimento e a possibilidade de expansão ("Expand").

Portanto, a flexibilidade está em aguardar até o último passo para maximizar os ganhos, neste cenário há somente cinco caminhos dos oito possíveis que indicam a expansão dentro das probabilidades simuladas. A seguir, a Figura 10 apresenta o resultado da análise do cenário moderado. 
A Teoria de Opções Reais na Gestão de Investimentos na Indústria 4.0: um Estudo de Caso

Figura 7 - Árvore Binomial de decisão - Projetos Encadeados: Cenário Moderado

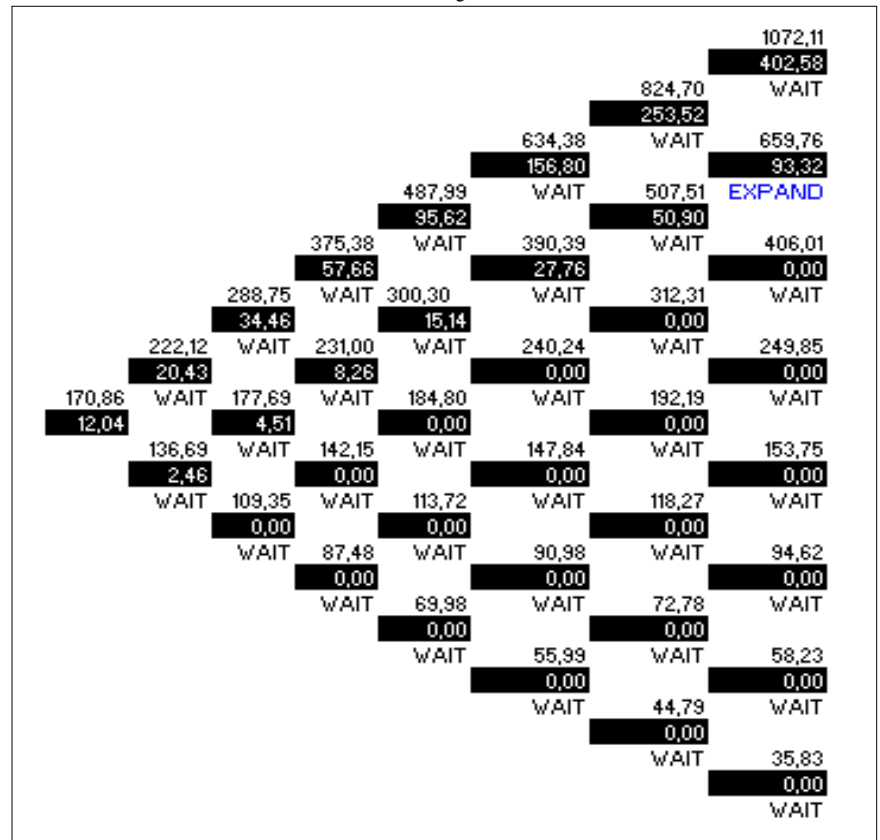

Fonte: Elaborado pelos autores.

No cenário moderado observa-se que para uma opção americana, os primeiros nós da árvore binomial indicam que a opção de esperar ("Wait") é maior do que no último período que indica o seu vencimento e a possibilidade de expansão ("Expand"). Portanto, a flexibilidade está em aguardar até o último passo para maximizar os ganhos, neste cenário há somente um caminho possível dos oito encontrados que indica a expansão dentro das probabilidades simuladas. A seguir, a Figura 11 apresenta o resultado da análise do cenário pessimista.

Figura 8 - Árvore Binomial de decisão - Projetos Encadeados: Cenário Pessimista

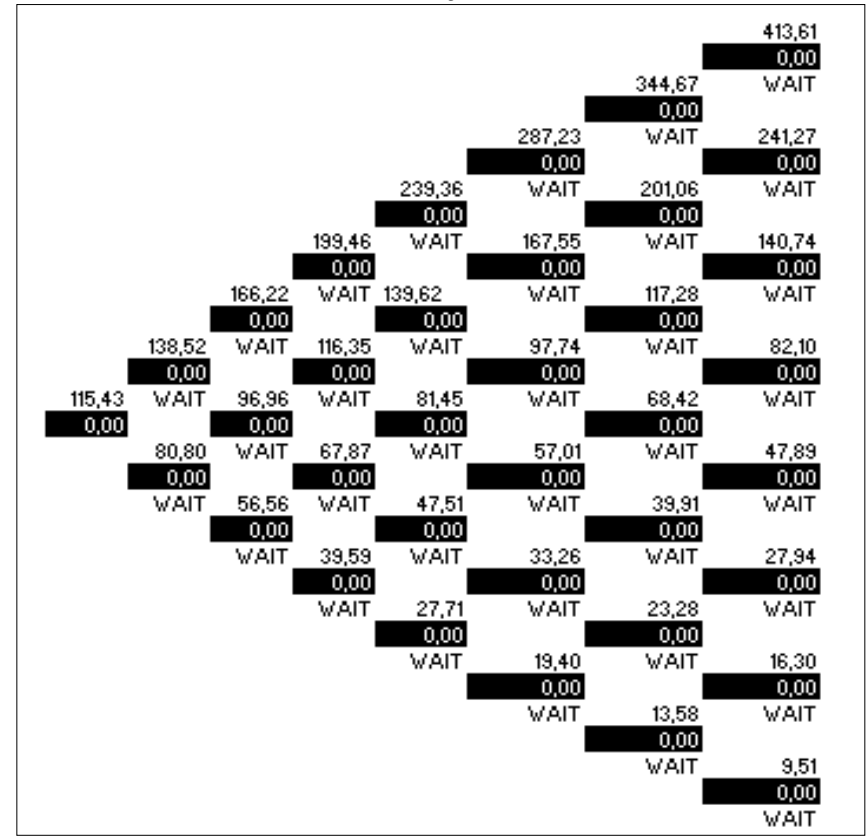

Fonte: Elaborado pelos autores.

Revista de Gestão, Finanças e Contabilidade - v. 10, n. 2, p. 60-85, mai./jun. 2020 ISSN 2238-5320, UNEB, Salvador/BA 


\section{A Teoria de Opções Reais na Gestão de Investimentos}

na Indústria 4.0: um Estudo de Caso

No cenário pessimista observa-se que para uma opção americana, indicam que não deve ser exercida a opção de expansão ("Expand”) para projetos encadeados. Portanto, a flexibilidade está em aguardar até um cenário melhor para que os investimentos tenham um retorno mais adequado.

De forma geral, as árvores de decisão tanto para o Projeto Isolado como para os Projetos Encadeados, retornaram como opção de expansão somente nos cenários otimistas e moderados. O cenário pessimista simulado não recomenda a expansão. Portanto, neste período em questão é indicado para o empresário do setor da Indústria de Máquinas e Equipamentos aguardar um momento mais propício para o investimento.

\subsubsection{Análise Dos Resultados Da Opção Real - Etapa 4}

O quarto e último passo é a realização da análise dos resultados obtidos através da ótica de Opções Reais.

Os valores do Valor Presente Líquido e os valores de Opção apresentados na seção anterior para o projeto isolado e os projetos indicam os resultados obtidos dentro desta análise de opção de expansão.

Agora para obter o resultado final para o valor presente líquido com flexibilidade, de acordo com COPELAND e ANTIKAROV (2002), para o projeto isolado e encadeado, utiliza-se a seguinte expressão:

$\mathrm{VPLf}=\mathrm{VPL}+\mathrm{VOR}$

Onde:

VPLf $=$ Valor presente líquido com flexibilidade

$\mathrm{VPL}=$ Valor presente líquido tradicional

VOR $=$ Valor das Opções Reais

Desta maneira obtém-se os resultados apresentados na Tabela 12 para os dois casos propostos.

Tabela 12 - Análise do Valor Presente líquido com flexibilidade

\begin{tabular}{l|l|l|l|l|l|l}
\hline \multirow{2}{*}{} & \multicolumn{3}{|c}{ Projeto Exemplo - Isolado } & \multicolumn{2}{c}{ Projetos Encadeados - Totais } \\
\cline { 2 - 7 } & Otimista & Moderado & Pessimista & Otimista & Moderado & Pessimista \\
\hline $\begin{array}{l}\text { Valor Presente } \\
\text { Líquido - Padrão }\end{array}$ & $\mathrm{R} \$ 62.034$ & $\mathrm{R} \$ 60.973$ & $\mathrm{R} \$ 43.293$ & $\mathrm{R} \$ 242.835$ & $\mathrm{R} \$ 170.858$ & $\mathrm{R} \$ 115.430$ \\
\hline $\begin{array}{l}\text { Valor da Opção } \\
\text { (VOR) }\end{array}$ & $\mathrm{R} \$ 18.540$ & $\mathrm{R} \$ 2.540$ & $\mathrm{R} \$ 0$ & $\mathrm{R} \$ 60.480$ & $\mathrm{R} \$ 12.040$ & $\mathrm{R} \$ 0$ \\
\hline $\begin{array}{l}\text { Valor presente } \\
\text { líquido com } \\
\text { flexibilidade }\end{array}$ & $\mathrm{R} \$ 80.574$ & $\mathrm{R} \$ 63.513$ & $\mathrm{R} \$ 43.293$ & $\mathrm{R} \$ 303.315$ & $\mathrm{R} \$ 182.898$ & $\mathrm{R} \$ 115.430$ \\
\hline
\end{tabular}

Fonte: Elaborado pelos autores.

Após a verificação dos resultados apresentados, conclui-se que a opção de expansão nos dois casos propostos dentro do cenário pessimista não é aconselhável. Quando avaliada a opção de expansão para um ambiente otimista, em cujo as variáveis de entrada são favoráveis, o investimento se torna mais aconselhável com maior probabilidade de retornos positivos para a empresa. 
Contudo, uma opção de expansão fornece à empresa a faculdade de expandir em diferentes mercados, produtos, tecnologias e estratégias ou para expandir suas operações atuais sob as condições adequadas.

No processo de transformação da Indústria de Máquinas e Equipamentos, no contexto da Indústria 4.0, a incorporação de novas tecnologias para captar, armazenar e processar informações dos processos produtivos, como neste caso de estudo, são formas de ilustrar as mudanças de patamar da competitividade da empresa e a retomada das receitas no setor.

Assim como apresentado em Minardi (2004), as rápidas adaptações às necessárias mudanças no ambiente empresarial são uma forma de se defender e prosperar no longo prazo. Sendo assim, é imprescindível acompanhar esses ciclos de transformações tecnológicas, sendo assertivo nos investimentos em novos projetos. E a metodologia aplicada a este estudo de caso ilustra como é possível identificar riscos e mitiga-los para obter maiores resultados para a empresa.

\section{CONCLUSÕES}

Nesse trabalho, por meio de um estudo de caso, foi proposta uma análise da transformação digital que vem ocorrendo através de iniciativas inovadoras no contexto da Indústria 4.0, que reúne um conjunto de tendências tecnológicas que estão sendo desenvolvidas para elevar o patamar de integração das cadeias produtivas e ganhos competitivos para a indústria e seus clientes.

Em essência, Indústria 4.0 envolverá a integração técnica dos computadores em grandes volumes de dados na fabricação e logística e o uso da Internet das Coisas e Serviços em processos industriais no desenvolvimento de fábricas inteligentes e conectadas. Isto terá implicações para a criação de valor, nos modelos de negócios, nos serviços e na organização do trabalho, além de impactar o padrão de consumo e de vida das sociedades.

As indústrias estão passando por uma transformação rápida, para que possam obter maiores ganhos financeiros da Era da Digitalização, potencializados pelos benefícios inerentes da tecnologia e do forte avanço competitivo. Embora as implementações atuais consistam em monitoramento de ativos, diagnósticos e análise fundamental, a atração de mudanças de mercado que mudam o jogo e a necessidade de uma forte conformidade regulatória estão direcionando investimentos em análise preditiva e otimização para a tomada de decisões. Superar barreiras como armazenamento e processamento de dados e falta de segurança robusta não será fácil.

Neste contexto, aplicação da Teoria das Opções Reais foi adotada neste trabalho e revelou-se ser de grande contribuição para o melhor uso dos recursos disponíveis para investimentos, buscando a mitigação de riscos para a empresa e seus clientes, além de identificar melhores pontos de entrada em projetos de inovação dentro do contexto da Indústria 4.0.

Foi possível ampliar abordagem na decisão de investimento em projetos, principalmente pela ampliação da complexidade tecnológica envolvida e os impactos na cadeia de valor. A otimização dos recursos destinados a melhoria nos processos de fabricação para que se possa embarcar no cenário da Indústria 4.0 torna-se amplo e necessário. Bem como, os desdobramentos de novas tecnologias na cadeia produtiva. 
O uso da metodologia das opções reais, deixa claro ampliação da realização de um investimento, uma vez que é possível avaliar um projeto que seja considerado de valia tecnológica e ao mesmo tempo possa encarar o mercado econômico atual do país. Usar o recurso financeiro de forma otimizada e estratégica, agregando solução aos clientes e agilidade em processos. De forma geral é com essa postura, com ferramental tecnológico e gestão adequada que se faz a diferença neste ambiente desafiador da Indústria 4.0.

No estudo de caso apresentado foi possível reunir os conceitos de inovação e tecnologia inerentes ao novo contexto da Indústria 4.0. Verificar a sua adequação em um caso prático e seus possíveis desdobramentos futuros.

O projeto analisado buscou incorporar tecnologias relacionados ao contexto da Era Digital, como foi apresentado na seção 4.4. Desta maneira provou-se que os conceitos de Indústria 4.0 apresentados no Capítulo 2 estavam aderentes ao objeto de estudo. Outro ponto de grande valia apresentado é a possibilidade de surgimento de novos projetos desdobrados deste estudo de caso inicial, com grandes chances de novas aplicações tecnológicas venham a ser incorporadas nesta mesma linha produtiva. Portanto, seguindo um caminho que alinhe os respectivos requisitos técnicos da indústria 4.0 e os recursos financeiros necessários para seus desenvolvimentos e implantações, podendo evoluir cada vez mais para uma fabricação inteligente capaz de tomadas de decisões autônomas, eficientes e seguras.

Em paralelo, o uso das Opções reais se mostrou uma ferramenta de impacto positivo no auxílio de avaliação de investimentos. O seu método em quatro passos possibilitou identificar no estudo de caso com opção de expansão, que a mitigação de riscos de investimentos em conjunto com a flexibilidade gerencial na decisão pode evoluir a capacidade de utilização dos recursos de uma empresa.

A grande contribuição desta pesquisa fica por conta da conexão de dois assuntos relevantes, a Indústria 4.0 e a Teoria das Opções Reais. Por um lado, o contexto amplo que envolve os conceitos de Indústria 4.0 e todas as suas oportunidades setor industrial, exigindo ferramentas técnicas de aplicações para as novas tecnologias no âmbito empresarial, abre a porta de métodos de análises de investimentos mais amplos.

Nesta linha, a Teoria das Opções Reais possibilita a ampliação na tomada de decisão em investimentos, buscando dar flexibilidade e mitigação de riscos. O estudo de caso conseguiu juntar estes dois assuntos e chegar a resultados relevantes quando é considerado um cenário de análise próximo ao real.

\section{REFERÊNCIAS}

ACCENTURE TECHNOLOGY (Org.). Industrial Internet of Things: Reimagine the Possibilities. 2016. Disponível em: <https://www.accenture.com/us-en/labs-insightindustrial-internet-of-things $>$. Acesso em: 19/11/2016.

ATZORI, L.; LERA, A.; MORABITO, G.. The internet of things: A survey. Computer networks, v. 54, n. 15, p. 2787-2805, 2010.

BAUERNHANSL, T.; TEN HOMPEL, Michael; VOGEL-HEUSER, Birgit (Ed.). Industrie 4.0 in Produktion, Automatisierung und Logistik: Anwendung, Technologien und Migration. Wiesbaden: Springer Vieweg, 2014. 
BUXMANN, P.; HESS, T.; RUGGABER, R.. Internet of services. Business \& Information Systems Engineering, v. 1, n. 5, p. 341, 2009.

CHUKWUEKWE, D. O. et al. Reliable, Robust and Resilient Systems: Towards Development of a Predictive Maintenance Concept within the Industry 4.0 Environment. In: EFNMS Euro Maintenance Conference. 2016.

CNI (Brasil). DESAFIOS PARA INDÚSTRIA 4.0 NO BRASIL. 2016. Disponível em: 〈http://www.pedbrasil.org.br/ped/artigos/079F8BA3E7E5281B.0 no Brasil.pdf〉. Acesso em: 19/11/2017.

CNI (Brasil). PESQUISA INÉDITA DA CNI MOSTRA CENÁRIO DA INDÚSTRIA 4.0 NO BRASIL. 2016. Disponível em: $<$ http://www.portaldaindustria.com.br/cni/imprensa/2016/05/1,88711/pesquisa-ineditada-cni-mostra-cenario-da-industria-4-0-no-brasil.html >. Acesso em: 21/06/2017

CONSULTING GROUP. Industry 4.0: the future of productivity and growth in manufacturing industries, Boston, 2015.

COPELAND, T. E.; ANTIKAROV, V. Opções reais: um novo paradigma para reinventar a avaliação de investimentos. Campus, 2002.

DAVIES, R. Industry 4.0. Digitalisation for productivity and growth. Briefing from EPRS. European Parliamentary Research Service, 2015.

DAVIS, J. et al. Smart manufacturing, manufacturing intelligence and demand-dynamic performance. Computers \& Chemical Engineering, v. 47, p. 145-156, 2012.

DIXIT, A. K.; PINDYCK, Robert S. Investment under uncertainty. Princeton university press, 1994.

HERMANN, M.; PENTEK, T.; OTTO, B. Design Principles for Industrie 4.0 Scenarios: A Literature Review: Working Paper No. 01, 2016.

KAGERMANN, H.; LUKAS, W.; WAHLSTER, W. Industrie 4.0: Mit dem Internet der Dinge auf dem Weg zur 4. industriellen Revolution. VDI nachrichten, v. 13, p. 11, 2011.

KULATILAKA N.; PEROTTI, E. C. Strategic growth options. Management Science, v. 44, n. 8, p. 1021-1031, 1998.

LEE, I.; LEE, K.. The Internet of Things (IoT): Applications, investments, and challenges for enterprises. Business Horizons, v. 58, n. 4, p. 431-440, 2015.

MELL, P.; GRANCE, T. The NIST definition of cloud computing. National Institute of Standards and Technology, 2011.

MINARDI, A. M. Accioly Fonseca. Teoria de opções aplicada a projetos de investimento. Revista de Administração de Empresas, v. 40, n. 2, p. 74-79, 2004.

MIRANDA, J. F. Metodologia de Análise de Investimentos em Distribuição utilizando Opções Reais no Novo Ambiente do Setor Elétrico Brasileiro. 2005. Tese de Doutorado. Dep. de Eng. Elétrica, UNIFEI/Itajubá, 156p, setembro, 2005. 
MONTEIRO, R. C. Contribuições da abordagem de avaliação de opções reais em ambientes econômicos de grande volatilidade-uma ênfase no cenário latinoamericano. 2003. Tese de Doutorado. Universidade de São Paulo.

MUN, J.. Real options analysis course: business cases and software applications. John Wiley \& Sons, 2003.

O'HALLORAN, D.; KVOCHKO, E. Industrial Internet of Things: Unleashing the Potential of Connected Products and Services. In: World Economic Forum. 2015. p. 40.

RFB - RECEITA FEDERAL DO BRASIL. Instrução Normativa RFB No 1700, de 14 de março de 2017. Dispõe sobre a determinação e o pagamento do imposto sobre a renda e da contribuição social sobre o lucro líquido das pessoas jurídicas e disciplina o tratamento tributário da Contribuição para o PIS/Pasep e da Cofins no que se refere às alterações introduzidas pela Lei $\mathrm{n}^{\mathrm{o}} 12.973$, de 13 de maio de 2014. Disponível em:< http://normas.receita.fazenda.gov.br/sijut2consulta/link.action?visao=anotado\&idAto= 5004>. Acesso 19/11/2017.

RIGOLON, F. J. Z.. Opções reais, análise de projetos e financiamentos de longo prazo. Revista do BNDES, Rio de Janeiro, v. 6, n. 11, 1999.

RUHNKA, J. C.; YOUNG, J. E. A venture capital model of the development process for new ventures. Journal of Business venturing, v. 2, n. 2, p. 167-184, 1987.

SEPPA, T.; LAAMANEN, T. Valuation of Venture Capital Investment: Empirical Investments. Working paper 2000. Disponível em: <http://www. realoptions. org/papers/LaamanenSeppa. Pdf>, 2000. Acesso em 19/11/2017

TRIGEORGIS, L. Real options and interactions with financial flexibility. Financial management, p. 202-224, 1993.

VALENTE, D. N. R. Decisões de investimento em condições de incerteza: uma abordagem com opções reais equivalentes. Tese de Doutorado. Universidade de São Paulo.

YOSHIMURA, E. K. et al. Opções reais aplicadas na análise da qualidade de investimentos na construção civil. 2008. Dissertação de mestrado. Dep. de Arquitetura e Construção, UNICAMP/Campinas. 